This is a postprint version of the following published document:

Peña-Bahamonde, J., Atencia, J. J., Pozuelo, J., Tarazona, M. P. y Mendicuti, F. (2013): New Insights on the Self-Organization of PEG/ $\alpha$-Cyclodextrin-Based Polyrotaxanes in Solution: An Experimental and Theoretical Study. Macromolecular Chemistry and Physics, 214 (24), pp.: 2801-2812.

DOI: $10.1002 / \operatorname{macp} .201300370$

(C) WILEY, 2013 


\title{
New Insights on the Self-Organization of PEG/ a -Cyclodextrin-Based Polyrotaxanes in Solution: An Experimental and Theoretical Study
}

\author{
Janire Peña-Bahamonde, José Joaquín Atencia, Javier Pozuelo, \\ María Pilar Tarazona, Francisco Mendicuti*
}

Size exclusion chromatography coupled with light scattering (SEC/MALS), dynamic light scattering (DLS), steady-state and time-resolved fl uorescence, as well as molecular dynamics (MD) simulations are used to study the behavior of several poly(ethylene glycol) (PEG)/ $\alpha$ cyclodextrins ( $\alpha$ CDs) polyrotaxanes (PRs) in solution. The number of CD units in any of the PRs studied is always smaller than that required to saturate the PEG chains. These PRs seem to aggregate in dimethyl

sulfoxide (DMSO) solution. The presence of hairpins in the non-saturated PRs contributes to diminishing their expected large dimensions. Intra- and inter-molecular interactions and forces responsible for hairpins and aggregation are investigated.

Keywords: fluorescence ; molecular dynamics ; poly(ethylene glycol) (PEG) ; polyrotaxane ; size exclusion chromatography

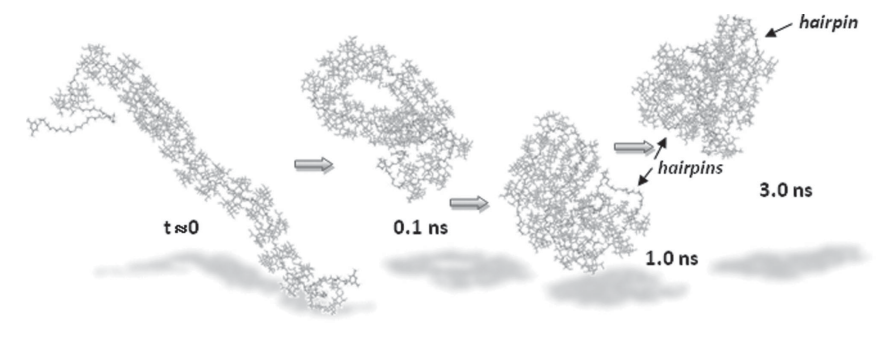

\section{Introduction}

In recent years, supramolecular polymers have attracted much research interest. ${ }^{[1-4]}$ A classic example of these supramolecular structures is polyrotaxanes (PRs), which are formed by the nonbonded interactions of hollow macrocycles threaded onto a single linear polymer chain. ${ }^{[4-9]}$ Cyclodextrins (CDs) are a more-common macrocycle. ${ }^{[10-16]}$ Among them, the most used are the native $\alpha$-, $\beta$-, and $\gamma \mathrm{CDs}$ composed of 6,7 , and $8 \mathrm{D}(+)$-glucopyranose units connected by $\alpha-1,4$-linkages, respectively. Their relatively hydrophobic cavities make the inclusion of a variety of guest molecules including polymers possible. The major driving forces for forming PRs are usually hydrophobic and van der Waals interactions between the $\mathrm{CD}$ and the polymer chain. ${ }^{\left[{ }^{[9]}\right.}$ The first PRs formed by spontaneous inclusion of linear polymers with CDs were reported more than 20 years ago and poly(ethylene glycol) (PEG)/ $\alpha \mathrm{CDs}$ were the first obtained in a crystalline state. ${ }^{[17,18]}$ The formation of these PRs depended not only on the nature and the molecular weight of the polymer but also on the cavity size. ${ }^{[19-22]}$ Thus, PEG only formed spontaneously inclusion complexes with $\alpha \mathrm{CD}$ s and $\gamma \mathrm{CD}$ in water but not with $\beta C D$ s, which require more extreme conditions. ${ }^{[23]} \mathrm{To}$ prevent unthreading in solution, terminal bulky groups were added at both ends. ${ }^{[9-16,19-22,24,25]}$ Differential thermal analysis (DTA) showed that the decomposition of these PRs occurred at higher temperatures than that of the free CDs, demonstrating the thermal stability of CDs in PRs. ${ }^{[26]}$ Approximately 2.3 oxyethylene units per $\alpha \mathrm{CD}$ were found when the chain was completely saturated. Head-to-head $(\mathrm{HH})$ orientation of $\mathrm{CDs}$ seemed to be more favorable than head-to-tail (HT) one. ${ }^{[24,27]}$

A wide variety of materials have been prepared from the PRs derived from PEG or other linear polymers and CDs, such as molecular tubes, ${ }^{[28,29]}$ drug carriers and 
delivery systems, ${ }^{[30]}$ multivalent ligands that possess rotating/sliding recognition groups, ${ }^{[31]}$ molecular wires using a $\mathrm{CD}$ molecular tube as insulator for conducting polymers, ${ }^{[32-36]} \mathrm{PR} /$ cellulose blend fibers showing good elongation properties, ${ }^{[37]}$ and cross-linked PR materials with diverse mechanical responses. ${ }^{[38-44]}$

One of the major problems with the characterization in solution of the PEG/CD-based PRs, particularly with high $\mathrm{CD}$ coverage, is that they are hardly soluble in water and most regular organic solvents, like dimethylformamide or pyridine, even though they could be good solvents of both guest and host components. Partial solubility in other solvents like dimethyl sulfoxide (DMSO) and sodium hydroxide solutions, ${ }^{[24,45]}$ dimethyl acetamide-containing lithium halide ${ }^{[46,47]}$ was also reported. Many reactions, modifications, and studies involving PEG/CD PRs have been performed in DMSO as solvent. ${ }^{[24,47-57]}$

Several authors have described a thixotropic viscosity behavior of PRs derived from PEG and $\alpha \mathrm{CD}$ s in DMSO at relatively concentrated solutions. ${ }^{[4,52,54-56]}$ This behavior is a consequence of the formation of physical aggregates between PR chains, which are reversibly broken by heating or by the application of a shear. Araki and Ito ${ }^{[52]}$ attributed this manner to a combination of intermolecular attractive $C D$ hydrogen bonding and the high rigidity, resulting from relatively high $\alpha \mathrm{CD}$ :PEG inclusion ratios (number of $\alpha \mathrm{CD}$ s per PEG chain) PRs. Travelet et al. ${ }^{[54]}$ demonstrated by SANS that these PRs behave like multiblock copolymers in DMSO. One block type consists of a rod-like tube made of 6-7 weakly stacked $\alpha \mathrm{CDs}$ threaded along the PEO chain. The other one is made up of naked polymer segments. In the case of PR/ DMSO-concentrated solutions at room temperature, the PR aggregates by forming nanocylinders, which consist of assemblies of $\alpha \mathrm{CD}$ :PEG rod-like tubes resulting from hydrogen-bonding interactions. More recently, ${ }^{[56]}$ the same authors studied the PR structure as a function of the temperature and $\alpha \mathrm{CD}$ :PEG ratio in DMSO-concentrated solutions. The behavior of the multiblock copolymers at $43{ }^{\circ} \mathrm{C}$ was again observed. When the PR mixtures were cooled down, gelation occurred. The gel structure is due to the formation of regular bundles containing naked PEG segments surrounded by nano-cylinders. Stoichiometry is a crucial parameter controlling the PR prealignment, selforganization (and PR flexibility), which is favored (unfavored) at high $\alpha$ CDs-to-PEG coverage degrees. Mayumi et al. ${ }^{[55]}$ used the same technique to study a PR of PEG ( $\approx 35 \mathrm{~kg} \mathrm{~mol}^{-1}$ ) with $\alpha \mathrm{CD}$ of $27 \%$ coverage at a lower DMSO concentration regime, and no aggregation was observed. CDs seemed to be distributed randomly along the entire PEG chain in the PR.

In order to clarify the behavior in solution (preferentially DMSO) of this type of PRs, in the present study we report the synthesis and characterization in solu- tion of some end-capped (with phenoxy or naphthoxy groups) PRs derived from PEG of $3.4,6.8$, and $13.8 \mathrm{~kg} \mathrm{~mol}^{-1}$ and native $\alpha$-cyclodextrin, $\alpha \mathrm{CD}$, named PR\#:CD:Ph or PR\#:CD:Nph (\# = 3k, 6k, or $10 \mathrm{k})$ and PRs, where $\alpha \mathrm{CDs}$ were modified with phenylisocyanate, $\alpha \mathrm{CD}(\mathrm{PhI})$, [PR\#:CD(PhI):Ph or PR\#:CD(PhI):Nph]. For this purpose size exclusion chromatography (SEC/MALS), dynamic light scattering (DLS), and fluorescence techniques were used. In addition, molecular dynamics (MD) simulations on isolated PR chains with different stoichiometries and $\alpha \mathrm{CD}$ orientations, as well as five PR chains placed in a periodic box, were performed to rationalize and explain the experimental behavior and identify the intra- and intermolecular interactions responsible for the PR formation and aggregation.

\section{Materials, Instrumentation, and Methods}

\subsection{Reagents and Solvents}

Dihydroxy-terminated PEG with weight-averaged molecular weights, $\bar{M}_{\mathrm{w}}$, of $3.4,6.8$, and $13.8 \mathrm{~kg} \mathrm{~mol}^{-1}\left(\bar{M}_{\mathrm{n}}\right.$, of 2.6 , 4.8, and $10.2 \mathrm{~kg} \mathrm{~mol}^{-1}$ ), coded PEG3k, PEG6k, and PEG10k, respectively, were obtained from Fluka and were dried under vacuum at $40^{\circ} \mathrm{C}$ prior to using. $\alpha \mathrm{CD}$ was obtained from Wacker-Ouímica Ibérica and was also dried under vacuum at $80{ }^{\circ} \mathrm{C}$. Other reagents and solvents, dichloromethane $\left(\mathrm{CH}_{2} \mathrm{Cl}_{2}\right)$ (anhydrous, 99.8\%), dimethylformamide (DMF) (anhydrous, 99.8\%), DMSO (anhydrous, 99.9\%), pyridine (99\%), $p$-toluenesulfonyl chloride ( $p$ $\mathrm{TsCl})$ (98\%), 3,5-dimethylphenol (99\%), 1-naphthol (Nph) (98\%), phenyl isocyanate (PhI) (98\%), and triethylamine $\left(\mathrm{Et}_{3} \mathrm{~N}\right)(99.5 \%)$, were from Sigma-Aldrich and were used as received. Toluene (99.7\%) and sodium hydride $(\mathrm{NaH})$ (55-65\% gas volumetric in paraffin oil) were from Fluka. Paraffin oil was rinsed off using $n$-hexane.

For fluorescence experiments, DMSO, methanol $(\mathrm{MeOH})$, and DMF (Aldrich, spectroscopic or HPLC grades, purity $\geq 99.7 \%$ ) were used as solvents. 2-Napthol and phenol were employed as model compounds for PR fluorescence measurements. DMSO (Aldrich, HPLC grade) and LiBr (Aldrich, purity > 99.9\%) were also used for gel-permeation chromatography (GPC) measurements.

\subsection{Polyrotaxane Synthesis}

Two families of PRs based in the above-mentioned PEGs and $\alpha \mathrm{CDs}$, end-capped with two different bulky groups, 3,5-dimethylphenol $(\mathrm{Ph})$ and 1-naphthol $(\mathrm{Nph})$, respectively, named PR\#:CD:Ph and PR\#:CD:Nph (\# = 3k, 6k, or 10k), were synthesized by using methods well documented in the literature (see brief description and Scheme S1, 
Supporting Information). ${ }^{[19,24,45,58]}$ A PEG10:Nph, used as reference system, was synthesized following the same procedures as in PRs.

The modification of the previous PRs with phenyliso-

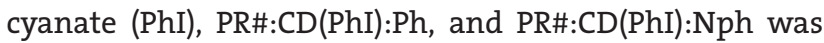
performed according to procedures published elsewhere (see brief description and Scheme S2, Supporting Information). ${ }^{[4]}$ All the products were freeze-dried and kept in vacuum up to their use.

\subsection{Instrumentation and Methods}

${ }^{1} \mathrm{H}$ NMR spectra at $500 \mathrm{MHz}$ for all PRs were recorded on a Bruker Avance spectrometer at room temperature. Spectra were measured with four accumulations and $2.18 \mathrm{~s}$ for acquisition time. Chemical shifts were referenced to the solvent, DMSO- $\mathrm{d}_{6}(\delta=2.50 \mathrm{ppm})$. Fourier Transform IR (FTIR) spectra were recorded from $\mathrm{KBr}$ pellets on a PerkinElmer GX 2000 (10 scans and $1 \mathrm{~cm}^{-1}$ resolution). Thermogravimetric analysis (TGA) for all PRs was obtained on a Perkin-Elmer STA 6000 system. After thoroughly drying at $50{ }^{\circ} \mathrm{C}$ for $10 \mathrm{~min}$, samples were recorded from 50 to $700{ }^{\circ} \mathrm{C}$ at a heating rate of $10{ }^{\circ} \mathrm{C} \mathrm{min}-1$ in a slow nitrogen flow $\left(20 \mathrm{~mL} \mathrm{~min}^{-1}\right)$.

SEC measurements were carried out using equipment that consisted of a pump (Waters, model 510), an injector (Waters, U6K), and two detectors: Optirex Interferometric Refractometer (RI) operating at $632.8 \mathrm{~nm}$ and a Dawn DSP-F multiangle light scattering (MALS) photometer, equipped with a He-Ne laser $(632.8 \mathrm{~nm})$, both from Wyatt Technology Corp. The chromatographic columns used, Styragel HR 4E, were kept in an oven at $50^{\circ} \mathrm{C}$. The eluent consisted of a $5 \times 10^{-4} \mathrm{M} \mathrm{LiBr}$ solution in DMSO that was passed through a $1.0 \mu \mathrm{m}$ cellulose nitrate filter (Whatman) and degassed prior to use. The flow rate was $0.4 \mathrm{~mL} \mathrm{~min}{ }^{-1}$. Repeated injections were made for each sample to ensure the reproducibility of the results. In all cases, the results were reproduced. The light scattering equation and the experimental procedure used to collect and process SEC/MALS data in order to obtain molecular weights were explained elsewhere. ${ }^{[59-61]}$ The value of $\mathrm{d} n / \mathrm{d} c$ for PRs in DMSO was measured in batch with the RI detector by using solutions of PR10:CD:Nph at different concentrations. The value obtained was $0.055 \mathrm{~mL} \mathrm{~g}^{-1}$, which is rather similar to the one reported ${ }^{[62]}$ for PRs from PEG and $\alpha \mathrm{CD}$ s in the same solvent.

DLS measurements were performed using a Malvern Zetasizer Nano Series operating a $4 \mathrm{~mW} \mathrm{He-Ne} \mathrm{laser} \mathrm{at}$ $633 \mathrm{~nm}$. Analysis was performed in DMSO, at an angle of $173^{\circ}$ and different temperatures, using $1 \mathrm{~cm}$ glass cuvettes.

Absorption spectra were recorded in a Lambda 35 Perkin Elmer UV-vis spectrophotometer. Steady-state and time-resolved fluorescence measurements were performed on SLM 8100C Aminco and FL900 Edinburgh Instruments spectrofluorometers, respectively. Decay intensity profiles were fitted to a sum of exponential decay functions $I(t)=\sum_{i=1}^{n} A_{i} e^{-t / \tau_{i}}$ by the iterative reconvolution method. ${ }^{[63]}$ The average lifetime of a multiple-exponential decay function was then defined as $\langle\tau\rangle=\sum_{i=1}^{n} A_{i} \tau_{i}^{2} / \sum_{i=1}^{n} A_{i} \tau_{i}$, where $A_{\mathrm{i}}$ is the pre-exponential factor of the component with a lifetime $\tau_{\mathrm{i}}$ of the multiexponential function intensity decay ${ }^{[64]}$ More details are included in the Supporting Information.

MD simulations were computed using Sybyl-X1.2 ${ }^{[65]}$ and the Tripos force field. ${ }^{[66]}$ Trajectories were performed on several isolated PRs named PR3:HTCD $n$ :Ph and $\mathrm{PR} 3: \mathrm{HTCD}_{n}: \mathrm{Ph}$ that were composed of: a) a $3 \mathrm{k}$ molecular weight Ph-end-labelled PEG chain (68 ethylene oxide units), which were initially placed in the all trans-conformation and b) a molecular channel that contains $n(=2,4$, $12,14,16$, or 20 ) non-distorted HH- or HT-oriented $\alpha \mathrm{CDs}$. These $\alpha \mathrm{CD}$ s were initially located uniformly and symmetrically distributed from the center of mass of the transPEG chain and their centers of mass were separated from each other by $\approx 8 \AA$. Figure S1 in the Supporting Information depicts an example of both types of PR configurations studied.

The potential energy was obtained as the sum of bond stretching, angle bending, torsional, van der Waals, electrostatics, and out-of-plane contributions. Charges were calculated for each repetitive unit and terminal group using MOPAC (AM1). ${ }^{[67]} \mathrm{CD}$ charges were those used previously by us. ${ }^{[68]} \mathrm{A}$ relative permittivity $\varepsilon=3.5$ was utilized in the vacuum. ${ }^{[27]}$ The simulations were started on minimized PR structures by using the simplex algorithm and the conjugate gradient $\left(0.15 \mathrm{kcal} \mathrm{mol}^{-1} \AA^{-1}\right)$ termination method. ${ }^{[69,70]}$

Each $3 \mathrm{~ns}$ MD simulation was started at $1 \mathrm{~K}$ and the temperature was increased at intervals of 10 degrees remaining in the intermediate states 300 fs until reaching the temperature of interest of $500 \mathrm{~K}$. Vibrations for bonds connecting hydrogen atoms were eliminated. Integration time was 2 fs and images were collected every 200 fs, providing 15000 conformations for each trajectory. The high temperature of $500 \mathrm{~K}$ allows for a broad sampling of the conformational space during the 3.0 ns MD trajectories.

The number of intra- and intermolecular hydrogen bonds (HBs) of the systems were obtained by assuming the presence of a HB, when the acceptor and hydrogen bonded to a donor are separated by a distance in the 0.8-2.8 $\AA$ interval and the angle formed by $\mathrm{O} . . . \mathrm{H}-\mathrm{O}$ ranges from $120^{\circ}$ to $180^{\circ}$.

To evaluate the intermolecular PR interactions, five $\mathrm{PR} 3: \mathrm{HHCD}_{20}: \mathrm{Ph} \mathrm{PR}$ chains were randomly distributed in a periodic boundary conditions (PBC) box of dimensions $27.6 \mathrm{~nm} \times 19.5 \mathrm{~nm} \times 19.5 \mathrm{~nm}$ and then a $1 \mathrm{~ns} M D$ 
Table 1. Molecular weight and composition of end-capped with 3,5-dimethylphenol and 1-naphtol polyrotaxanes.

\begin{tabular}{|c|c|c|c|c|}
\hline Polyrotaxane & $\begin{array}{c}\text { Number of CD } \\
\text { per chain }^{\mathrm{a})}\end{array}$ & $\begin{array}{c}\text { Coverage }^{\mathrm{b})} \\
{[\%]}\end{array}$ & EG/CD molar ratio $\left.{ }^{c}\right)$ & $\begin{array}{c}\bar{M}_{\mathrm{n}}^{\mathrm{d})} \\
{\left[\mathrm{g} \mathrm{mol}^{-1}\right]}\end{array}$ \\
\hline PR3:CD:Ph & 19 & 74 & 3.1 & 21000 \\
\hline PR6:CD:Ph & 33 & 70 & 3.3 & 37000 \\
\hline PR10:CD:Ph & 39 & 39 & 5.9 & 48000 \\
\hline PR3:CD:Nph & 16 & 62 & 3.7 & 18000 \\
\hline PR6:CD:Nph & 29 & 61 & 3.8 & 33000 \\
\hline PR10:CD:Nph & 41 & 41 & 5.7 & 50000 \\
\hline
\end{tabular}

a) Number of $\alpha \mathrm{CD}$ s per chain, calculated by ${ }^{1} \mathrm{H}$ NMR spectroscopy; ${ }^{\mathrm{b})} \mathrm{A}$ molar ratio of 2.3 ethylene glycol (EG) repeat units per CD means a $100 \%$ coverage; ${ }^{[24]}$ c) The molar ratio that shows the EG units shared for each $\alpha \mathrm{CD}$; ${ }^{\mathrm{d})}$ Number-averaged molecular weight obtained from the ${ }^{1} \mathrm{H}$ NMR spectroscopy analysis of the PEG $(\delta=3.51 \mathrm{ppm})$ and $\alpha \mathrm{CD}(\delta=4.80 \mathrm{ppm})$ proton signals ${ }^{[24,71]}$; The values of the initial PEG $\bar{M}_{\mathrm{n}}$ were $2.6,4.8$, and $10.2 \mathrm{~kg} \mathrm{~mol}^{-1}$.

trajectory, following similar protocols as for each isolated PR, was simulated.

\subsection{Polyrotaxanes Characterization}

The composition for the non-modified PRs was obtained by ${ }^{1} \mathrm{H}$ NMR spectroscopy. (Figure S2, Supporting Information). The $\alpha \mathrm{CD} / \mathrm{PEG}$ molar ratios were estimated by comparison of $\alpha \mathrm{CD} \mathrm{C}(1)-\mathrm{H}(\delta=4.80 \mathrm{ppm})$ and PEG ( $\delta=3.51 \mathrm{ppm})$ proton signals as described elsewhere. ${ }^{[24,71]}$ Table 1 summarizes the stoichiometry ratios for the PRs. The PEG chain covered by $\mathrm{CDs}$ (percentage of coverage) was also obtained under the assumption that a PEG chain is saturated with CDs, when the molar PEG:CD fraction is 2.3:1. ${ }^{[24,58]}$ As collected in Table 1, the percentage of coverage (EG/CD molar ratios) for non-modified PRs decreases (increases) with PEG molecular weight, but the values obtained for PRs with smallPEG chains, 3k and 6k, are significantly higher (lower) than that for the $10 \mathrm{k}$ ones in both series. The results are in good agreement with those obtained by Zhao and Beckham. ${ }^{[58]}$ Nevertheless, for checking purposes, the number of CDs per PR was also estimated from the $2 \mathrm{I}_{1 \mathrm{H}} / \mathrm{I}_{\mathrm{mH}}$ ratios, where $\mathrm{I}_{1 \mathrm{H}}$ and $\mathrm{I}_{\mathrm{mH}}$ are the integrated areas under the $\alpha \mathrm{CD} \mathrm{C}(1)-\mathrm{H}$ $(\delta=4.80 \mathrm{ppm})$ and the methyls from the PEG terminal Ph groups ( $\delta=2.22 \mathrm{ppm}$ ), respectively. ${ }^{[58]}$ No relevant stoichiometric differences were obtained with this method and the previous one. ${ }^{[24,58,71]}$ Unfortunately, NMR spectroscopy signals are too small to obtain any reliable results for PRs derived from the largest molecular-weight PEG (10k). As collected in Table 1, the use of $\mathrm{Nph}$ or Ph stoppers does not imply significant stoichiometry changes. The numberaveraged molecular weights for non-modified PRs, estimated from the ${ }^{1} \mathrm{H}$ NMR spectroscopy analysis of the PEG $(\delta=3.51 \mathrm{ppm})$ and $\alpha \mathrm{CD}(\delta=4.80 \mathrm{ppm})$ proton signals, ${ }^{[24]}$ are depicted in the last column of Table 1.

${ }^{1} \mathrm{H}$ NMR spectra for PRs modified with phenyliso-

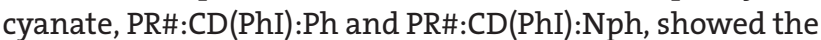
carbamate $(\delta=9.66 \mathrm{ppm})$ and phenylisocyanate aromatic ring $(\delta=7.46,7.18,6.92 \mathrm{ppm}$ ) signals (Figure S3, Supporting Information). The complete interpretation of the ${ }^{1} \mathrm{H}$ NMR spectroscopy of all modified PRs was difficult because of the small intensity of the anomeric peaks from $\alpha \mathrm{CD}$.

Assignments of bands in the FTIR spectra for the PRs (Figure S4, Supporting Information) agreed with the proposed structures. Moreover, the lack of a signal at $2267 \mathrm{~cm}^{-1}$ confirms the absence of free phenylisocyanate in all the modified PRs. ${ }^{\text {72] }}$

The thermogravimetric analysis (TGA) was also performed on all the PR samples. Figure 1 shows the thermograms for the four PRs derived from PEG10k, together with that for $\alpha \mathrm{CD}$. No weight loss was detected in the 50-184 ${ }^{\circ} \mathrm{C}$ temperature range for any of the non-modified PRs. First, free $\alpha \mathrm{CD}$ showed a slow decrease in weight at $50{ }^{\circ} \mathrm{C}$ having approximately $95 \%$ in weight left at $122{ }^{\circ} \mathrm{C}$. Subsequently, $\alpha \mathrm{CD}$ showed a rapid decrease in weight over $280{ }^{\circ} \mathrm{C}$ with approximately $18 \%$ in weight left as residue at $430{ }^{\circ} \mathrm{C}$. TGA of non-modified PRs showed a one-stage weight-loss pattern that corresponded to the

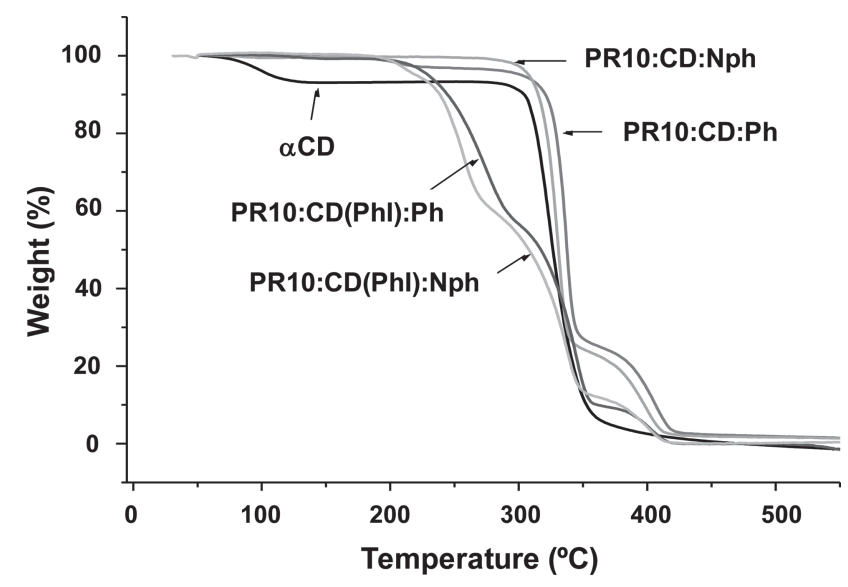

Figure1. Tlermogravimetric analysis for $\alpha$ CDandPRsbasedin PEG1ok. 
degradation of the $\alpha \mathrm{CD}$ and PEG moieties that occurred at the temperature ranges of $275-359{ }^{\circ} \mathrm{C} .{ }^{[19,42,73]}$ Although the thermogram of the PEG chain was not shown in the figure, the degradation of the PEG chain occurred at the temperature ranges of $168-350^{\circ} \mathrm{C}$. Thus, the $\mathrm{CD}$ stabilizes the PEG chains in all PRs because the degradation of all PRs starts $100^{\circ} \mathrm{C}$ after the PEG degradation.

The TGA profiles of the modified phenylcarbamate PRs with end-bulky Nph or Ph groups, PR\#:CD(PhI):Nph and $P R \#: C D(P h I): P h$, were very similar to the TGA curves that are well referenced in the literature for other polymers, such as polyurethanes ${ }^{[74]}$ and cellulose carbamates. ${ }^{[72,75,76]}$ They present a three-stage weight-loss pattern consisting of the degradation of the PhI, $\alpha \mathrm{CD}$, and PEG components in the 180-260, 260-360, and 360-420 ${ }^{\circ} \mathrm{C}$ temperature ranges, respectively. The first stage reflects the percentage of phenylcarbamate anchored to the $\alpha \mathrm{CD}$ and involves two substages. In the first one (ca. $180-220^{\circ} \mathrm{C}$ ), the thermal cleavage of the urethane bond, which dissociates into the starting components phenylisocyanate and hydroxyl group of the $\mathrm{CD}$, takes place. ${ }^{[74,75]}$ The second substage $\left(220-260^{\circ} \mathrm{C}\right)$ is due to the degradation of the phenylisocyanate regenerated in the first substage and it can be used to calculate the percentage of phenylisocyanate groups in the CDs. ${ }^{[75]}$ The results, collected in the second column of Table 2, indicate that roughly one-third of hydroxyl groups were substituted.

\section{Results and Discussion}

\subsection{Size Exclusion Chromatography (SEC-MALS)}

The upper panel of Figure 2 depicts the chromatograms through the RI signals (broken lines) and one of the MALS signals at $90^{\circ}$ (solid lines) for the different PRs. The light scattering signals are proportional to the product of molecular weight and concentration and they obviously have a different shape than the RI signals, which are proportional

Table 2. Percentage of substitution of phenylisocyanate per polyrotaxane and hydroxyl group respectively, obtained by TGA.

\begin{tabular}{lccc}
\hline Polyrotaxane & $\begin{array}{c}\text { PhI weight } \\
\text { in PR } \\
\text { [\%] }\end{array}$ & $\begin{array}{c}\text { Substituted } \\
\text { hydroxyl } \\
\text { groups } \\
\text { [\%] }\end{array}$ & $\begin{array}{c}\overline{\mathbf{M}}_{\mathbf{n}} \\
\text { [g mol }^{-1} \text { ] }\end{array}$ \\
\hline PR3:CD(PhI):Ph & 32 & 24.3 & 31000 \\
PR6:CD(PhI):Ph & 39 & 33.5 & 61000 \\
PR10:CD(PhI):Ph & 31 & 25.5 & 70000 \\
PR3:CD(PhI):Nph & 36 & 29.5 & 28000 \\
PR6:CD(PhI):Nph & 37 & 31.2 & 52000 \\
PR10:CD(PhI):Nph & 34 & 29.3 & 76000
\end{tabular}
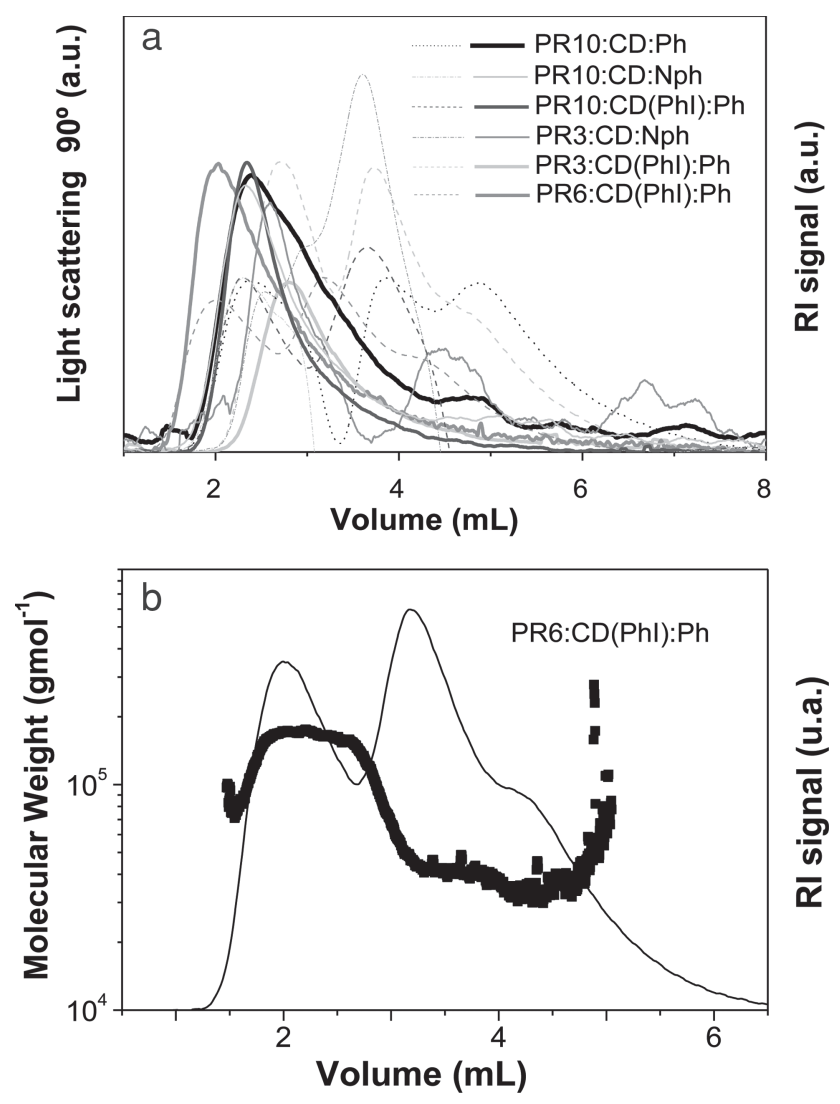

Figure 2. a) Chromatogram traces of some PRs in DMSO. Light scattering, MALS, signals (solid lines), and refractive index, RI, signals (broken lines) plotted versus elution volume. b) Molecular weight (fi lled squares) and RI signal (solid line) versus elution volume for PEG6:CD(Phl):Ph.

to the concentration. Chromatograms are multimodal and are formed by the overlapping of several narrower peaks, RI traces show two well-defined peaks, and in some cases, a shoulder at high elution volumes. We do not have any conclusive explanation for this shoulder. However, the molecular weights are close to those obtained for the second peak and, in all samples, they are higher than molecular weights of free PEG chains.

The MALS detector permits the determination of the molecular weight of the species in solution as they elute the columns, and the bottom of Figure 2 displays the molecular weight dependence on elution volume superimposed on the chromatogram trace (RI signal) for PR6:CD(PhI) $\mathrm{Ph}$ as an example. The accuracy of the molecular weight decreases with increasing elution volumes, thus the determination of the lower molecular weights that appear at the end of the chromatograms is less precise. Nevertheless, Figure $2 \mathrm{~b}$ clearly shows that molecular weight diminishes as the elution volume increases, as expected. However, the decrease is very mild (i.e., the molecular weight remains approximately constant) for each one of the first two peaks 
Table 3. Weight-averaged molecular weight for the two chromatogram peaks of PRs and ratio between molecular weights of firstpeakandisolatedPRchain.

\begin{tabular}{lccc}
\hline Polyrotaxane & \multicolumn{2}{c}{$\overline{\mathbf{M}}_{\mathrm{w}}$} & M(first peak)/M(PR chain) \\
\cline { 2 - 3 } & First peak & $\begin{array}{c}\text { Second } \\
\text { peak }\end{array}$ & \\
\hline PR3:CD(PhI):Ph & 106000 & 31000 & 3.0 \\
PR6:CD(PhI):Ph & 169000 & 41000 & 2.6 \\
PR10:CD(PhI):Ph & 276000 & 40000 & 3.7 \\
PR10:CD:Ph & 105000 & 22000 & 2.3 \\
PR10:CD:Nph & 96000 & - & 2.1
\end{tabular}

that form the chromatogram but there is an abrupt change between them. The molecular weight dependence of the remaining PRs behaves in a similar manner. The molecular weight of the PR3:CD:Nph was difficult to obtain because its solution in DMSO was reddish.

Weight-average molecular weights, $\bar{M}_{\mathrm{w}}$, for the PRs are displayed in Table 3. For the PR10:CD:Nph, the RI signal has two overlapped peaks whose separation is not enough to determine the molar mass of the second peak (see last row of Table 3). The molecular weights of the first peak of the chromatograms are too large to correspond to isolated chains of PRs since they are two to three times their expected values calculated from NMR spectroscopy and TGA data (Table 1 and 2). Thus, this peak suggests that aggregation among PR chains occurs. The molecular weights of the second peak, collected in Table 3, are much closer to the ones estimated from NMR spectroscopy data (Table 1 and 2) and thus, they might be attributed to isolated PR chains. The differences among them are due to the fact that the samples are polydisperse and the chromatographic separation between aggregates and isolated chains is not complete, as can be seen in Figure 2. Information about the aggregates can be inferred from the molecular weights of the first peak and their relationship with those of isolated chains. The molecular weights of the aggregates increase as the PEG size increases, as can be noticed for $\mathrm{PR \# CD(PhI):Ph} \mathrm{in} \mathrm{Table} \mathrm{3,} \mathrm{whereas} \mathrm{the} \mathrm{ratio}$ between the molecular weight of the aggregate and the molecular weight of the corresponding PR chain (fourth column of Table 3) for the three PRs is fairly constant. Thus, the polymer forms aggregates in DMSO with a number of chains that seem not to depend on the size of the PEG. When comparing molecular weights for the three PRs derived from PEG10k, it was first observed that the type of end groups, $\mathrm{Ph}$ or $\mathrm{Nph}$, has no influence on the molecular weight and second, that the superficial modification in the $\mathrm{CD}$ seems to favor the aggregation, increasing the number of chains in the aggregate. The aggregation of PRs derived from PEG and $\alpha \mathrm{CD}$ in DMSO has been described in the literature, as well as earlier in this paper, and depends on the $\alpha \mathrm{CDs}$ to-PEG coverage, solution concentration, and temperature. ${ }^{[44,52,54-56]}$

\subsection{Dynamic Light Scattering}

DLS measurements of PR10:CD:Nph (35\% CD coverage) solutions in DMSO at $\approx 2.4 \mathrm{mg} \mathrm{mL}^{-1}$ (similar concentration as SEC measurements) were carried out at three different temperatures, 25,50 , and $75^{\circ} \mathrm{C}$. The intensity distribution at $50{ }^{\circ} \mathrm{C}$ (the temperature used in SEC/MALS) showed two broad peaks at an apparent hydrodynamic radius of $9 \pm 3$ and $80 \pm 40 \mathrm{~nm}$. These results are in good agreement with the aggregation behavior found in both SEC/MALS. These two distinct peaks also appear at $25^{\circ} \mathrm{C}$ with a similar broadness, although they are slightly displaced toward larger sizes. At $75{ }^{\circ} \mathrm{C}$, the aggregate peak is clearly shifted toward smaller values of approximately $30 \pm 20 \mathrm{~nm}$ and the second peak appears at ca. $2 \mathrm{~nm}$. This fact would indicate that the temperature rise opposes the aggregation and thus the size of the aggregates diminishes, as one could expect and as was described by several authors. ${ }^{[4,52,54-56]}$ After the data acquisition at $75^{\circ} \mathrm{C}$, the PR solution was cooled right back to $25^{\circ} \mathrm{C}$. The intensity distribution profiles of the cooled solution were similar to those previously collected at this temperature, indicating that aggregation in DMSO is a reversible process. Although the DLS measurements must be handled cautiously due to the polydispersity of the samples, they support the aggregation behavior of PRs.

\subsection{Fluorescence}

As depicted in Figure 3a, the fluorescence spectrum of a dilute solution of the naphthyl (Nph) end-labelled PEG chain (PEG10:Nph) in DMSO upon excitation of naphthalene moiety (295 $\mathrm{nm}$ ) showed: i) a typical monomer emission band $(\approx 340 \mathrm{~nm})$, similar to the one observed for 2-naphthol model; ii) an excimer band ( $\approx 425 \mathrm{~nm}$ ) due to intramolecular end-to-end group interactions. Figure $3 \mathrm{a}$ also depicts emission spectra for PR10:CD:Nph and PR3:CD:Nph, which only exhibited the single monomer band. The absence of an excimer band is a consequence of the formation of relatively extended conformations for the PEG immersed in the $\alpha \mathrm{CD}$ s channel, which hinders the conformations where both end groups come close together. This did not occur for the PEG free polymer chain (i.e., PEG10:Nph).

Figure 3 (right) shows fluorescence emission spectra for DMSO dilute solutions of phenol (Ph) model and PRs containing 3,5-dimethylphenoxide $(\mathrm{Ph})$ end groups, either with unmodified (native) $\alpha \mathrm{CDs}$ (PR\#:CD:Ph) or modified 

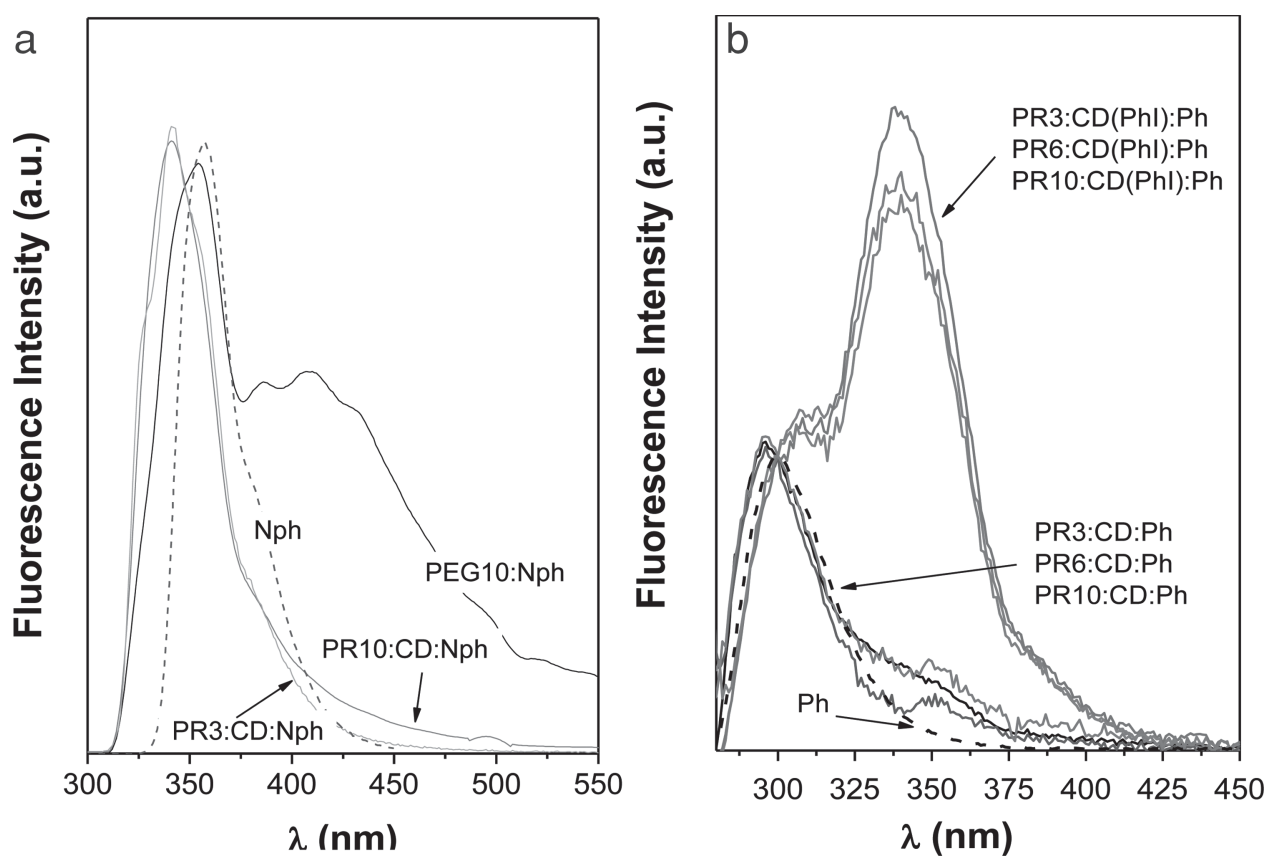

Figure 3. Emission spectra for DMSO dilute solutions of (a) 2-naphthol (Nph), PEG10:Nph and two end-labelled PRs with Nph groups at 25 ${ }^{\circ} \mathrm{C}$ and (b) phenyl end-labelled PR\#:CD:Ph and PR\#:CD(Phl):Ph PRs at the same experimental conditions.

ones with PhI groups, PR\#:CD(PhI):Ph, upon excitation of $275 \mathrm{~nm}$. Spectra for PR\#:CD:Ph, regardless of molecular weight, show features similar to those naphthalene end-labelled PRs (PR\#:CD:Nph), exhibiting a single-Phend-group monomer band, centered now at $\approx 295 \mathrm{~nm}$. $\mathrm{PR \# :CD(PhI):Ph,} \mathrm{however,} \mathrm{showed} \mathrm{an} \mathrm{additional} \mathrm{excimer}$ band, whose maximum is placed around $425 \mathrm{~nm}$. As the PR concentration was very low and its change did not affect the excimer-to-monomer ratios and presumably, as for PR\#:CD:Ph, end-to-end excimers are quite unlikely, the latter emission was attributed either to interactions between $\mathrm{PhI}$ groups within each $\mathrm{CD}(\mathrm{PhI})$ or between adjacent $\mathrm{CD}(\mathrm{PhI}) \mathrm{s}$ in the $\mathrm{PR}$, or probably to both. Whatever the solvent used, no excimers were observed for the PR\#:CD:Ph (and PR\#:CD:Nph) series. However, the

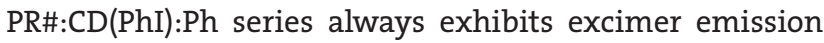
bands, whose intensity depends on the solvent nature but not on the PR molecular weight. This reinforces the idea that short-range phenyl group interactions from $\mathrm{CD}(\mathrm{PhI}) \mathrm{s}$ are involved. Table S1 ini the Supporting Information collects the excimer-to-monomer intensity ratios for Ph endlabelled PRs in different solvents.

Emission spectra (Figure S5, Supporting Information) for PEG10:Nph and PR10:CD:Nph solutions of DMSO/ EtOH mixtures by keeping polymer concentration constants at $\left(0.016 \times 10^{-3} \mathrm{M}\right)$ upon excitation of the $\mathrm{Nph}$ chromophore were also recorded. Results for PEG10:Nph show an increase in the fluorescence intensity upon increasing the EtOH content (solvent polarity decreasing), which is also accompanied by a slight decrease of the excimer-to-monomer ratios. PR10:CD:Nph and the Nph model compound, which obviously do not display excimer bands, exhibit the opposite behavior, an emission decreasing with the EtOH content. This may indicate that Nph end groups in the PR10:CD:Nph behave like the model compound in each solvent. Nph groups in PR10:CD:Nph are more exposed to the solvent than the same groups in the PEG10:Nph.

Weighted average lifetimes $<\tau$ for PEG10:Nph and PR10:CD:Nph solutions in DMSO/EtOH mixtures at $25^{\circ} \mathrm{C}$ were also obtained from analysis of the fluorescence intensity decays $\left(\lambda_{\mathrm{em}}=340 \mathrm{~nm}\right)$. Decay intensity profiles were bi-exponential with components around 2-3 ns (5-7 ns) and 7-8 ns (8-10 ns) for PEG10:Nph (PR10:CD:Nph). As a consequence, $<\tau>$ was always shorter for PEG10:Nph than for PR10:CD:Nph dilute solutions, probably because monomer emission is quenched by excimer formation. $<\tau>$ values for PR10:CD:Nph, whose end groups are more exposed to the solvent, decrease with ethanol content from $9.8 \mathrm{~ns}$ (DMSO) to $7.7 \mathrm{~ns}$ (40\% DMSO/EtOH), whereas for the different PEG10k:Nph solutions, whose chromophores are apparently more shielded from the solvent, the remaining constant $\approx 6.7 \mathrm{~ns}$ hardly changes at the same temperature.

With the purpose of reinforcing the experimental findings on the presence of the PR aggregation, the intermolecular phenol to naphthol energy transfer efficiency $\Phi_{\mathrm{ET}}$, was evaluated for an equimolar PR10:CD:Ph and PR10:CD:Nph $\left(0.14 \times 10^{-3} \mathrm{M}\right.$ each) mixture in DMSO at $25{ }^{\circ} \mathrm{C}$. The efficiency was defined as: ${ }^{[77]}$ 


$$
\frac{\Phi_{\mathrm{ET}}}{1-\Phi_{\mathrm{ET}}}=\frac{\phi_{\mathrm{D}} I_{\mathrm{A}}}{\phi_{\mathrm{A}} I_{\mathrm{D}}}
$$

where $\phi_{\mathrm{D}}$ and $\phi_{\mathrm{A}}$ are the fluorescence quantum yields ${ }^{[78]}$ for individual PR10:CD:Ph $\left(0.14 \times 10^{-3} \mathrm{M}\right)$ and PR10:CD:Nph $\left(0.14 \times 10^{-3} \mathrm{M}\right)$ DMSO dilute solutions upon excitation, both at $270 \mathrm{~nm} . I_{\mathrm{A}}$ and $I_{\mathrm{D}}$ are the integrated areas under the emission Nph and Ph bands, respectively, obtained for the equimolar mixture upon the same excitation wavelength. The emission spectra for PR10:CD:Ph and PR10:CD:Nph and the mixture in DMSO at $25^{\circ} \mathrm{C}$ are depicted in Figure $\mathrm{S} 6$ in the Supporting Information.

Equation 1 provides $\Phi_{\mathrm{ET}}=0.45$. The Förster radius for the Ph-to-Nph transfer is around $1.6 \mathrm{~nm} \cdot{ }^{[79]}$ At the concentrations used $\left(\approx 0.14 \times 10^{-3} \mathrm{M}\right)$, a simple calculation of the average of the distances between chromophores gives a value of around $15 \mathrm{~nm}$. At this distance, ten times larger than Förster radius, the efficiency for Ph-to-Nph energy transfer should be zero. The large efficiency can only be explained under the assumption that the PRs in DMSO solution aggregate.

\subsection{Circular Dichroism}

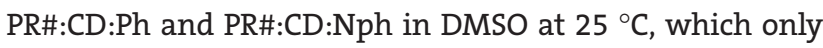
contain $\mathrm{Ph}$ or Nph terminal groups, respectively, hardly exhibited any induced circular (ICD) dichroism signal. The ICD signal, if it appeared, could be attributed to the possible interaction of $\mathrm{Ph}$ or Nph chromophores with the closest $\mathrm{CD}$ quiral macrorings located at both ends of the channel. The absence might presumably be a consequence of the low CD coverage of the PRs studied. PR\#:CD(PhI):Ph, however, showed a negative spectrum in the $260-280 \mathrm{~nm}$ absorption range, which was attributed to the quirality of the $\mathrm{CD}(\mathrm{PhI})$ itself.

\subsection{Molecular Dynamics Simulations}

End-to-end distances, root-mean-square radius of gyration, and PEG-CD and CD-CD per CD unit interaction energy averages obtained from analysis of the $3 \mathrm{~ns}$ MD trajectories for PEG3:Ph and PR3:CD $\mathrm{CD}_{n} \mathrm{Ph}(n=2,4,8,12,14,16$, and 20) containing HH- or HT-oriented CDs are collected in Table S2 in the Supporting Information. In agreement with the fluorescence spectra, the average of the distances between the center of mass of terminal Ph groups for any of the PRs studied are larger than the minimum requirements for the formation of intramolecular excimers. ${ }^{[80]}$ For the end-labelled PEG chain, PEG3:Ph, these averages are also larger than those expected for a PEG chain that, as experimentally observed, exhibited fluorescence emission from intramolecular excimers. Nevertheless, histories of the distances between the center of mass of Ph end groups
(Figure S7, Supporting Information), reveal that PEG3:Ph can adopt, during the trajectory, conformations where $\mathrm{Ph}$ groups are close together and capable of forming intramolecular excimers. As stated before, $\mathrm{Ph}-\mathrm{Ph}$ distances for any of the PR3:CD $: P h$ studied are relatively large to form excimers, but too short if compared with the distance obtained for the all trans-conformation of a PEG3k chain $(\approx 24.5 \mathrm{~nm})$. According to some MD calculations reported by us, ${ }^{[27]}$ the end-to-end distances for a totally saturated PEG3k (100\% coverage), containing a population of trans states for all the torsional angles of the oxyethylene units in the $80-90 \%$ range, was approximately $23 \mathrm{~nm}$.

In addition, PEG-CD interaction energies, whatever the $\mathrm{CD}$ orientations ( $\mathrm{HH}$ or $\mathrm{HT}$ ) were, showed a stabilization of the system upon the increasing of $n$. Furthermore, the interaction of each $\mathrm{CD}$ bonded with its neighbor, measured as $\mathrm{CD}-\mathrm{CD} / n$ energy interaction, contributed favorably to the formation of PRs, becoming more negative as $n$ increased. This interaction was more favorable for HH-oriented PRs than HT ones. Harada et al. ${ }^{[26,81]}$ attributed this stabilization to the presence of intermolecular $C D-C D$ hydrogen bonds, which are more numerous for $\mathrm{HH}$ sequences. However, the calculated PEG-CDbinding energies also favored the $\mathrm{HH}$ sequences over the $\mathrm{HT}$ ones by $3-8 \%$. According to these calculations, the PEG might stabilize by capturing as many $\mathrm{CDs}$ as its length permits. However, for the PRs used in our experiments the PEG chains were not saturated by CDs. Entropic effects obviously played an important role in PR formation. The mean-square radius of gyration $\left\langle s^{2}\right\rangle^{1 / 2}$ for PRs was in the 11-22 $\AA$ range and it evidently increased with $n$. Comparison of the values for HH and HT PRs, resulted in larger values for the HT ones, most likely attributed to the less effective $C D-C D$ and PEG-CDs interactions obtained for HT CD-oriented PRs as compared with the $\mathrm{HH}$ ones. Unfortunately, $\left\langle s^{2}\right\rangle^{1 / 2}$ can only be obtained by SEC/MALS from the angular dependence of scattered light, when the polymer sizes exceed the $\lambda / 20$ value of the wavelength of incident radiation in order to notice this angular dependence. Apparently, this is not the case with this PR series.

The average of the distances $\langle d\rangle$ between the center of mass of adjacent CD units for HH- and HT-oriented PRs containing 16 and 20 PEG units were calculated (Table S3, Supporting Information). Two quite distinguishable $\langle d\rangle$ values were obtained. The first one with $\langle d\rangle\langle 11-12 \AA$, which correspond to nearly parallel adjacent $C D$ pairs; and a second one with $\langle d\rangle>12-13 \AA$. The last distance also corresponds to neighbor CDs between which, the PEG chain folds back producing a reversal in the direction of the PR chain (hairpin). Then, both portions of the PR stand nearly parallel with $C D$ of each branch laterally interacting. In fact these interactions, to which $\mathrm{HB}$ between CDs presumably contribute, are responsible for the stabilization of the folded structure. 


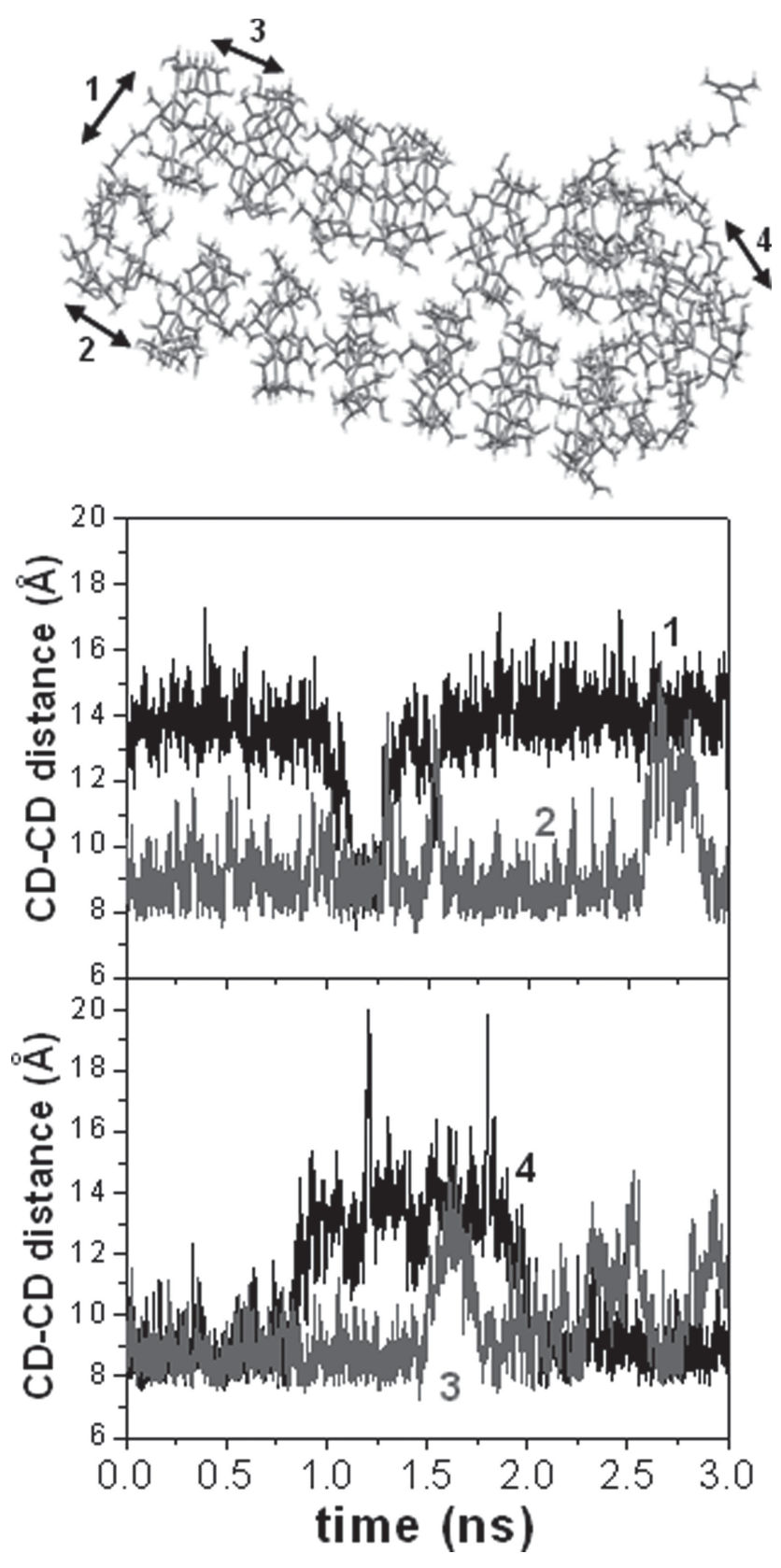

Figure 4. Histories of distances between the center of mass of some pairs of adjacent CDs obtained from the analysis of the $3 \mathrm{~ns}$ MD trajectories for PR3:HTCD ${ }_{16}$ :Ph. A snapshot of the PR trajectory (time $=0.2 \mathrm{~ns}$ ) is superimposed, showing the distances whose histories are represented.

Figure 4 shows the histories during the MD trajectory for the distances between the center of mass of some $C D$ pairs for PR3CD ${ }_{16} \mathrm{HT}$. The larger distance, as depicted in the superimposed figure, is responsible for the hairpin in the PR chain. A simple calculation of the number of intermolecular HBs between CDs of both PR portions at both sides of the hairpin for PR3CD ${ }_{16} \mathrm{HT}$ provides an average of $4.4 \pm 2.3 \mathrm{HBs}$ from the 15000 conformations.

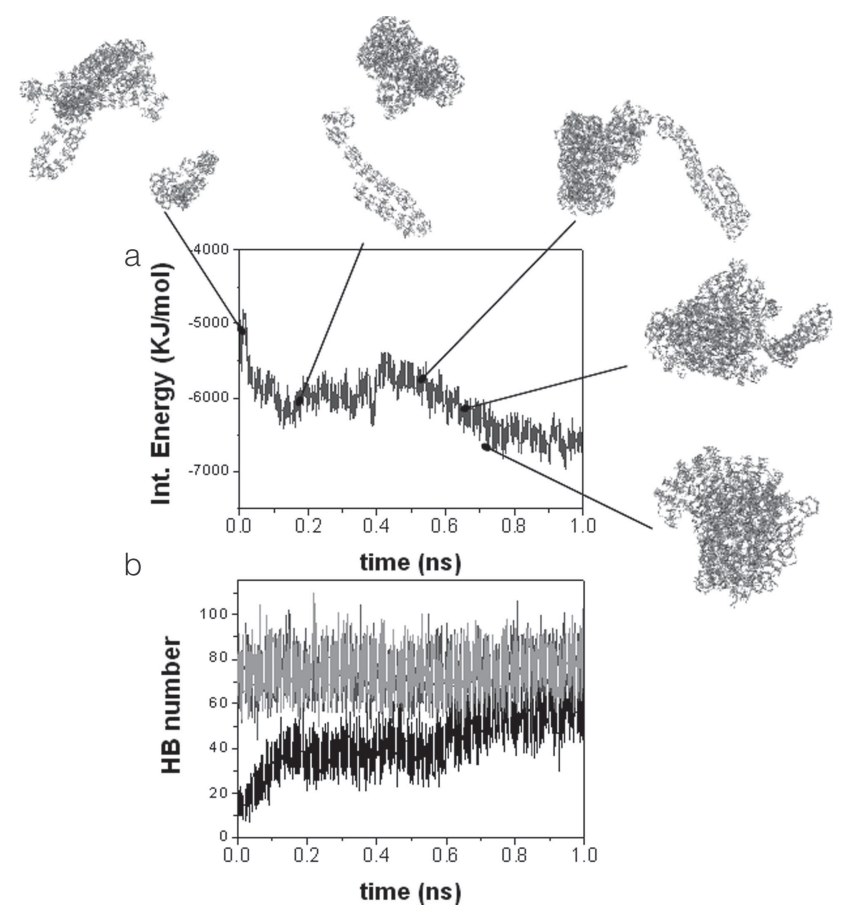

Figure 5. Histories of (a) binding energies per PR unit and (b) number of intermolecular hydrogen bonds (HBs) between PR chains (in black) and intramolecular ones for two individual PR chains obtained from the analysis of the $1 \mathrm{~ns} M D$ trajectory for fi ve PR3:HHCD16:Ph chains in a periodic box. The structures of the system at different times are superimposed.

Nevertheless, some of them have a maximum of 16 of these HB interactions. The number of hairpins does not depend on the HT or HH CD orientation. The presence of hairpins makes the dimensions of the unsaturated PR decrease considerably. Loethen et al. ${ }^{[82]}$ reported AFM images for a PEG $\left(1500 \mathrm{~kg} \mathrm{~mol}^{-1}\right)$ with $\alpha \mathrm{CD}$ PRs evaporated from DMSO, indicating the presence of uniformly distributed topographical features that correspond to: i) fully threaded PEG with $\alpha \mathrm{CD}$ PR ( $\approx 13.4 \mathrm{~nm}$ length); ii) structures of $\approx 8 \mathrm{~nm}$ resulting from the partially threaded linear PR containing hairpins, and iii) larger species from the presence of aggregates of PRs.

Aggregation was also investigated from analysis of the $1 \mathrm{~ns}$ MD trajectory of five PR3:HHCD ${ }_{20}: \mathrm{Ph}$ chains, which initially were randomly distributed in a $\mathrm{PBC}$ box. Undoubtedly the results, as Figure 5 depicts, prove that portions of each single PR chain tend to self-associate intra-molecularly through the formation of hairpins, where portions of the chain interact side by side and where $\mathrm{HB}$ interactions contribute to the stabilization. Moreover, PRs tend to spontaneously aggregate in the vacuum and this association is accompanied by favorable attractive intermolecular interactions between PRs. Whereas the number of total intramolecular HBs in the PR chains keeps almost constant during the entire MD 
trajectory, the number of HBs between CDs from different PR chains increases upon association contributing to the aggregate stabilization as shown in Figure 5. These results are in good agreement with the behavior found by SEC/ MALS, DLS, and fluorescence techniques.

\section{Conclusion}

The SEC/MALS technique allows us to obtain the molecular weight distributions and stoichiometries (4-17 ethylene oxide units per $\mathrm{CD}$ ) of several PRs, which seem to aggregate in DMSO solution. Whereas the PR aggregation does not seem to depend on the size of the PEG chain and the type of anchored end groups, the superficial modification of $\mathrm{CD}$ with phenylisocianate increases the aggregation numbers. PR aggregation decreases with temperature and it seems to be a reversible process. The absence of intramolecular excimers for phenyl- or naphthyl-end-labelled PRs infers that they adopt relatively extended conformations (at least more than the free PEG chain). The relatively high intermolecular energy transfer efficiency between $\mathrm{Ph}$ and Nph chromophores from the end groups of PR chains also agrees with the presence of aggregates in solution. $\mathrm{MD}$ calculations prove that CD-PEG and CD-CD (per CD unit) energy interactions are attractive, both increasing with the $\mathrm{CD}$ content. $\mathrm{HH}$ sequences are more favorable than HT ones. The presence of hairpins in the (non-saturated) PR chains contributes to lowering their expectedly large dimensions. Calculations also infer that PR chains spontaneously aggregate. The process is accompanied by an increase in the number of hydrogen bonds between CDs of different $\mathrm{PR}$ chains. Interaction energies are also favorable to aggregation.

\section{Acknowledgements:}

This work was supported by the University of Alcalá (GC2011-002 and UAH2011/EXP-036) and Nanomod (MAT2010-17091) from the Spanish Ministerio de Ciencia e Innovación. The authors acknowledge the assistance of $M$. L. Heijnen with the preparation of the manuscript.

\section{References}

[1] L. Brunsveld, B. J. B. Folmer, E. W. Meijer, R. P. Sijbesma, Chem. Rev. 2001, 101, 4071.

[2] J.-M. Lehn, Polym. Int. 2000, 51, 825.

[3] W. H. Binder, R. Zirbs, Adv. Polym. Sci. 2007, 207, 1.

[4] A. Harada, Supramolecular Polymer Chemistry, Wiley-VCH Verlag GmbH \& Co. KGaA, Weinheim, Germany 2012, p. 372

[5] A. Harada, Acc. Chem. Res. 2001, 34, 456.

[6] T. Takata, N. Kihara, Y. Furusho, Adv. Polym. Sci. 2004, 171, 1.

[7] A. Harada, A. Hashidzume, Y. Takashima, Adv. Polym. Sci. 2006, 201, 1.

[8] J. Araki, K. Ito, Soft Matter 2007, 3, 1456.

[9] A. Harada, A. Hashidzume, H. Yamaguchi, Y. Takashima, Chem. Rev. 2009, 109, 5974.

[10] S. A. Nepogodiev, J. F. Stoddart, Chem. Rev. 1998, 98, 1959.

[11] In Comprehensive Supramolecular Chemistry: Cyclodextrins, Vol. 3, (Eds: J. Szejtli, T. Osa), Pergamon, Oxford, UK 1996, p. 693.

[12] V. T. D'Souza, K. B. Lipkowitz, Chem. Rev. 1998, 98, 1741.

[13] E. Engeldinger, D. Armspach, D. Matt, Chem. Rev. 2003, 103, 4147.

[14] A. Douhal, Cyclodextrins Materials Photochemistry, Photophysics and Photobiology, Elsevier, Amsterdam 2006.

[15] H. Dodziuk, Cyclodextrins and Their Complexes: Chemistry, Analytical Methods, Applications, Wiley-VCH Verlag $\mathrm{GmbH}$ \& Co. KGaA, Weinheim, Germany 2008, p. 489.

[16] F. Davis, S. Higson, Macrocycles: Construction, Chemistry and Nanotechnology Applications, John Wiley \& Sons, Chichester, UK 2011.

[17] A. Harada, M. Kamachi, Macromolecules 1990, 23, 2821.

[18] G. Wenz, B. Keller, Angew. Chem. 1992, 104, 201.

[19] A. Harada, J. Li, M. Kamachi, Macromolecules 1993, 26, 5698.

[20] A. Harada, Carbohydr. Polym. 1997, 34, 183.

[21] J. Li, A. Harada, M. Kamachi, Polym. J. 1994, 26, 1019.

[22] A. Harada, J. Li, M. Kamachi, Macromolecules 1994, 27, 4538.

[23] K. A. Udachin, L. D. Wilson, J. A. Ripmeester, J. Am. Chem. Soc. 2000, 122, 12375.

[24] A. Harada, J. Li, M. Kamachi, J. Am. Chem. Soc. 1994, 116, 3192.

[25] A. Harada, H. Yamaguchi, in Synthesis of Polymers: New Structures and Methods, (Eds: D. A. Schlüter, C. Hawker, J. Sakamoto), John Wiley \& Sons, New York 2012, p. 1113.

[26] A. Harada, J. Li, M. Kamachi, Nature 1992, 356, 325.

[27] J. Pozuelo, F. Mendicuti, W. L. Mattice, Macromolecules 1997, 30,3685 .

[28] A. Harada, J. Li, M. Kamachi, Nature 1993, 364, 516.

[29] S. Samitsu, J. Araki, T. Shimomura, K. Ito, Macromolecules 2008, 41, 5385.

[30] T. Ooya, N. Yui, J. Controlled Release 2002, 80, 219.

[31] N. Yui, T. Ooya, Chem. Eur. J. 2006, 12, 6730.

[32] T. Shimomura, T. Akai, T. Abe, K. Ito, J. Chem. Phys. 2002, 116, 1753.

[33] T. Akai, T. Shimomura, K. Ito, Synth. Met. 2003, 135-136, 777.

[34] A. Farcas, M. Grigoras, J. Optoelectron. Adv. Mater. 2000, 2, 525.

[35] A. Farcas, E. G. Hitruc, Dig. J. Nanomater Bios. 2011, 6, 1649.

[36] A. Farcas, A.-M. Resmerita, A. Stefanache, M. Balan, V. Harabagiu, J. Org. Chem. 2012, 8, 1505.

[37] J. Araki, T. Kataoka, N. Katsuyama, A. Teramoto, K. Ito, K. Abe, Polymer 2006, 47, 8241.

[38] Y. Okumura, K. Ito, Adv. Mater. 2001, 13, 485.

[39] G. Fleury, G. Schlatter, C. Brochon, G. Hadziioannou, Polymer 2005, 46, 8494.

[40] G. Fleury, G. Schlatter, C. Brochon, G. Hadziioannou, Adv. Mater. 2006, 18, 2847. 
[41] G. Fleury, G. Schlatter, C. Brochon, C. Travelet, A. Lapp, P. Lindner, G. Hadziioannou, Macromolecules 2007, 40, 535.

[42] X.-S. Wang, H.-K. Kim, Y. Fujita, A. Sudo, H. Nishida, T. Endo, Macromolecules 2006, 39, 1046.

[43] J. Araki, T. Kataoka, K. Ito, Soft Matter 2008, 4, 245.

[44] C. Travelet, G. Schlatter, P. Hebraud, C. Brochon, A. Lapp, G. Hadziioannou, Langmuir 2009, 25, 8723.

[45] A. Harada, J. Li, T. Nakamitsu, M. Kamachi, J. Org. Chem. 1993, 58, 7524.

[46] J. Araki, K. Ito, J. Polym. Sci., Part A: Polym. Chem. 2005, 44, 532.

[47] J. Araki, K. Ito, J. Polym. Sci., Part A: Polym. Chem. 2006, 44, 6312.

[48] T. Ooya, N. Yui, J. Controlled Release 1999, 58, 251.

[49] T. Ooya, M. Eguchi, N. Yui, J. Am. Chem. Soc. 2003, 125, 13016.

[50] M. Tamura, A. Ueno, Chem. Lett. 1998, 27, 369.

[51] M. Tamura, A. Ueno, Bull. Chem. Soc. Jpn. 2000, 73, 147.

[52] J. Araki, K. Ito, Polymer 2007, 48, 7139.

[53] S. Samitsu, J. Araki, T. Shimomura, K. Ito, Macromolecules 2008, 41, 5385.

[54] C. Travelet, G. Schlatter, P. Hebraud, C. Brochon, A. Lapp, D. V. Anokhin, D. A. Ivanov, C. Gaillard, G. Hadziioannou, Soft Matter 2008, 4, 1855.

[55] K. Mayumi, H. Endo, N. Osaka, H. Yokoyama, M. Nagao, M. Shibayama, K. Ito, Macromolecules 2009, 42, 6327.

[56] C. Travelet, P. Hebraud, C. Perry, C. Brochon, G. Hadziioannou, A. Lapp, G. Schlatter, Macromolecules 2010, 43, 1915.

[57] N. Jarroux, P. Guégan, H. Cheradame, L. Auvray, J. Phys. Chem. B 2005, 109, 23816.

[58] T. Zhao, H. W. Beckham, Macromolecules 2003, 36, 9859.

[59] R. Medrano, M. T. R. Laguna, E. Saiz, T. M. Pilar, Phys. Chem. Chem. Phys. 2003, 5, 151.

[60] M. T. R. Laguna, J. Gallego, F. Mendicuti, E. Saiz, M. P. Tarazona, Macromolecules 2002, 35, 7782.

[61] G. Marcelo, F. Mendicuti, E. Saiz, M. P. Tarazona, Macromolecules 2007, 40, 1311.

[62] T. Kume, J. Araki, Y. Sakai, K. Mayumi, M. Kidowaki, H. Yokoyama, K. Ito, J. Phys.: Conf. Ser. 2009, 184.

[63] D. V. O'Connor, W. R. Ware, J. C. Andre, J. Phys. Chem. 1979, $83,1333$.

[64] J. R. Lakowicz, Principles of Fluorescence Spectroscopy, 3rd ed., Springer, New York 2006, p. 97.

[65] Tripos International, (2009), 1699 South Hanley Rd., St. Louis, Missouri 63144, USA.

[66] M. Clark, R. D. Cramer III, O. N. Van, J. Comput. Chem. 1989, 10, 982.
[67] M. J. Frisch, G. W. Trucks, H. B. Schlegel, G. E. Scuseria, M. A. Robb, J. R. Cheeseman, J. A. Montgomery, Jr., T. Vreven, K. N. Kudin, J. C. Burant, J. M. Millam, S. S. Iyengar, J. Tomasi, V. Barone, B. Mennucci, M. Cossi, G. Scalmani, N. Rega, G. A. Petersson, H. Nakatsuji, M. Hada, M. Ehara, K. Toyota, R. Fukuda, J. Hasegawa, M. Ishida, T. Nakajima, Y. Honda, O. Kitao, H. Nakai, M. Klene, X. Li, J. E. Knox, H. P. Hratchian, J. B. Cross, V. Bakken, C. Adamo, J. Jaramillo, R. Gomperts, R. E. Stratmann, O. Yazyev, A. J. Austin, R. Cammi, C. Pomelli, J. W. Ochterski, P. Y. Ayala, K. Morokuma, G. A. Voth, P. Salvador, J. J. Dannenberg, V. G. Zakrzewski, S. Dapprich, A. D. Daniels, M. C. Strain, O. Farkas, D. K. Malick, A. D. Rabuck, K. Raghavachari, J. B. Foresman, J. V. Ortiz, O. Cui, A. G. Baboul, S. Clifford, J. Cioslowski, B. B. Stefanov, G. Liu, A. Liashenko, P. Piskorz, I. Komaromi, R. L. Martin, D. J. Fox, T. Keith, M. A. Al-Laham, C. Y. Peng, A. Nanayakkara, M. Challacombe, P. M. W. Gill, B. Johnson, W. Chen, M. W. Wong, C. Gonzalez, J. A. Pople, MOPAC (AM1), included in the Gaussian 03 package,Gaussian 03, Revision C.02, edition, Gaussian, Inc., Wallingford, CT, USA 2004.

[68] J. Pozuelo, J. M. Madrid, F. Mendicuti, W. L. Mattice, Comput. Theor. Polym. Sci. 1996, 6, 125.

[69] Y. Brunel, H. Faucher, D. Gagnaire, A. Rassat, Tetrahedron 1975, 31, 1075.

[70] W. H. Press, S. A. Teukolsky, W. T. Vetterling, B. P. Flannery, Numerical Recipes: The Art of Scientific Computing, 3rd ed., Cambridge University Press, Cambridge 2007.

[71] C. Teucher, C. C. Michel, F. Hauser, D.-Y. Park, H. W. Beckham, G. Wenz, Macromolecules 2013, 46, 2.

[72] W. Mormann, U. Michel, Carbohydr. Polym. 2002, 50, 201.

[73] A. Harada, Coord. Chem. Rev. 1996, 148, 115.

[74] K. I. Aly, Polym. Int. 1999, 48, 773.

[75] J. Gironés, M. T. B. Pimenta, F. Vilaseca, C. A. J. F. de, P. Mutje, A. A. S. Curvelo, Carbohydr. Polym. 2007, 68, 537.

[76] A.-A. M. A. Nada, S. Kamel, M. El-Sakhawy, Polym. Degrad. Stab. 2000, 70, 347.

[77] J. Bravo, F. Mendicuti, E. Saiz, W. L. Mattice, Macromol. Chem. Phys. 1994, 195, 3411.

[78] F. Mendicuti, W. L. Mattice, Polym. Bull. 1989, 22, 557.

[79] I. B. Berlman, Handbook of Fluorescence Spectra of Aromatic Molecules, 2nd ed., Academic Press, New York 1973.

[80] J. Guillet, Polymer Photophysics and Photochemistry: An Introduction to the Study of Photoprocesses in Macromolecules, Cambridge University Press, London 1985, p. 141.

[81] A. Harada, M. Okada, J. Li, M. Kamachi, Macromolecules 1995, 28, 8406.

[82] S. Loethen, T. Ooya, H. S. Choi, N. Yui, D. H. Thompson, Biomacromolecules 2006, 7, 2501. 